\title{
TEMPORAL AND SPATIAL VARIATIONS OF AMBIENT DOSE EQUIVALENT RATE IN URBAN AND RURAL SITES
}

\author{
LJILJANA GULAN ${ }^{*}$ \\ ${ }^{1}$ Faculty of Natural Sciences and Mathematics, University of Priština, Kosovska Mitrovica, Serbia
}

\begin{abstract}
This study deals with the results of measuring the ambient dose equivalent rates conducted in test field. The impacts of temporal and weather variations (wind, precipitation, moisture, temperature) as well as spatial characteristics (rural and urban sites) on the ambient dose equivalent rate were analyzed. Mean ambient dose equivalent rate in rural site $(142 \mathrm{nSv} / \mathrm{h})$ is higher than in urban site $(128 \mathrm{nSv} / \mathrm{h})$. The reason is difference in altitude and also the difference in the local geology. Although an increasing of temperature, decreasing the moisture in air, and slowing down the wind speed during the observed period showed tendency of stability the ambient dose equivalent rate, no correlation was found between ambient dose equivalent rate and any parameter.
\end{abstract}

Keywords: Ambient dose equivalent rate, Variation.

\section{INTRODUCTION}

Background radiation, which is registered under normal conditions, originates from cosmic radiation, natural and anthropogenic radionuclides in the soil, air and ground surface (UNSCEAR, 2000). It is characteristic for a certain area, because it depends on the geology of a terrain and an altitude. Cosmic radiation consists mainly of protons and radiations which appear in proton interactions with atoms in atmosphere. At sea level contribution to the dose equivalent relates to muons (over $70 \%$ ), electrons and photons $(\sim 15 \%)$, neutrons $(10 \%)$, protons and charged pions $(1-2 \%)$. Contribution to external dose rate from directly ionizing and photon component is $32 \mathrm{nSv} / \mathrm{h}$, and $7.8 \mathrm{nSv} / \mathrm{h}$ from neutron component (UNSCEAR, 2008); contribution from radionuclides in air $\left({ }^{7} \mathrm{Be}\right.$ and $\left.{ }^{22} \mathrm{Na}\right)$ to the dose rate is below 1 $\mathrm{nSv} / \mathrm{h}$, and average contribution from radon and decay products outdoors is $2.5 \mathrm{nSv} / \mathrm{h}$ (Bossew et al., 2017).

It is known that the dose rate from photon and ionizing component varied with latitude, but the variation is small. The dose rate is about $10 \%$ lower at the geomagnetic equator than at high latitudes; the variability due to the solar cycle is also estimated to be about $10 \%$ (UNSCEAR, 2008). The ionizing component strongly depends on altitude; a variation of absorbed dose rate in air by a factor of 4 was measured in China for the same latitude, but different altitude (Wang, 2002). The cosmic ray dose rate at elevations above sea level was estimated according to the following equation (Bouville \& Lowder, 2002):

$$
E_{1}(z)=E_{1}(0)\left[0.21 \cdot e^{-1.649 z}+0.79 \cdot e^{0.4528 z}\right]
$$

where $E_{1}(0)$ is the dose rate at sea level and $\mathrm{z}$ is the altitude in kilometres.

\footnotetext{
* Corresponding author: ljiljana.gulan@pr.ac.rs PHYSICS
}

The production of cosmogenic radionuclides is greatest in the upper stratosphere and it is dependent not only on altitude but also on latitude.

Naturally occurring radionuclides of terrestrial origin are present in all environmental media, but in various degrees. These radionuclides with half-lives comparable to the age of the earth as well as their decay products exist in sufficient amount and can contribute to population exposure. Natural radiation in soil and on the ground surface originates from ${ }^{40} \mathrm{~K}$ and radionuclides in series ${ }^{238} \mathrm{U},{ }^{235} \mathrm{U}$ and ${ }^{232} \mathrm{Th}$, and anthropogenic radiation appears after nuclear weapon tests and nuclear accidents. This terrestrial component gives important contribution to the dose rate. The contribution of ${ }^{137} \mathrm{Cs}$ to the ambient dose equivalent rate is more significant in areas affected by the Chernobyl accident. The worldwide average contribution to external dose rate from terrestrial gamma radiation outdoors is estimated to $70 \mu \mathrm{Sv} / \mathrm{y}$ (UNSCEAR, 2008).

The dose rate in air changes from place to place and over time, because the diversity of soil composition affects the dose variation more than cosmic radiation (Gulan \& Spasović, 2017). The variation of terrestrial gamma radiation is usually greater than the variation of cosmic radiation. Therefore, it is important and desirable to get information on background radiation by measuring the gamma absorbed dose rate or ambient dose equivalent rate in the environment, where possible. This can serve as a useful database in the case of accidents.

Various meteorological conditions (temperature, wind, moisture, precipitation) can influence the variation in the values of the measured ambient dose equivalent rates. The maximum value of ambient dose equivalent rate in ground level air reaches at the end of summer and beginning of autumn, because of increased amount of autumn precipitation and difference in air and soil temperatures (Serbian Radiation Protection and Nuclear Safety Agency, 2016; Lebedyte et al., 
2003). It was observed that ambient dose equivalent rate increased during heavy rain which appeared after long drought, but when rain stopped, it decreased slightly (Lebedyte et al., 2003).

Soil receives heat from Sun and indirectly heats the air thus raising the temperature of the lower layers of the atmosphere. Moisture (humidity) is very changeable component of the atmosphere. The speed and direction of the wind are unstable due to turbulence. The wind draws air from the soil due to the Magnus effect above the uneven soil surface. Metrological conditions forming turbulent air mixing can influence the variation in ambient dose equivalent rate due to radon decay products for 6-17\% (Lebedyte et al., 2003).

The higher levels of background radiation are associated with volcanic rock masses (granite), and lower levels with sedimentary rocks (Stojanovska et al., 2016; Abba et al., 2017) and Quaternary geological background (Sanusi et al., 2014).

The aim of this study was to measure the ambient dose equivalent rates of test field in the rural and urban sites of the town Kruševac, and then analyze the spatial and temporal variations according to the preliminary results of the radiation levels.

\section{EXPERIMENTAL}

\section{Materials and methods}

Radiation measuring instruments calibrated in terms of ambient dose equivalent have been widely used for the purpose of radiation protection. In this study the Geiger counter RADEX model RD $1503^{+}$was used for measurements of ambient dose equivalent rate in air. The measurement with this detector is based on four averaged measurements which have been made within 40 seconds. RADEX model RD1503 operates in the interval of ambient dose equivalent rates from 0.05 to $9.99 \mu \mathrm{Sv} / \mathrm{h}$ and in the temperature range from $-18{ }^{\circ} \mathrm{C}$ to $65{ }^{\circ} \mathrm{C}$. Measurement uncertainty for gamma radiation is $\pm 15 \%$ (RADEX, 2017; Gulan \& Spasović, 2017). The natural radiation of terrestrial origin, as well as radiation from radionuclides in the air (decay products of radon, $\mathrm{Be}-7$ and $\mathrm{Na}-$ 22 in the atmosphere) is measured by RADEX.

Two measuring points, located at a relative distance of 20 $\mathrm{km}$ and different in altitudes, were selected in order to determine the spatial and temporal variations of ambient dose equivalent rates, as well as the influence of weather on the measuring values. The rural site is located at $304 \mathrm{~m}$ above sea level, and the urban site is $137 \mathrm{~m}$ above sea level. The geological units labeled as Quaternary and Neogene are mostly lowland landscapes. The Quaternary and Neogene unit often covers the rocks derived from nearby igneous and metamorphic rock, i.e. Jastrebac and Kopaonik mountains (Vučković et al., 2016). The measurements of ambient dose equivalent rate were carried out at $1 \mathrm{~m}$ above the ground in the period from 07.10.2017-21.10.2017. Some authors reported diurnal variations of ambient dose equivalent rate: the maximums are at 3-6 a.m., and minimums are at 3-6 p.m., (Lebedyte et al., 2003). For this reason the measurements were conducted between 1 and 2 p.m. every day at the same time, in order to get reliable diurnal values.

Since meteorological conditions can have a significant impact on the ambient dose equivalent rate measurements, parameters such as wind speed, temperature, moisture, precipitation were noted during measurements.

\section{RESULTS AND DISCUSSION}

Ambient dose equivalent rate, the values of wind speed, moisture, temperature during 15 days of measurements in test field (rural and urban sites) are presented in Table 1 and Table 2 , respectively. The measurement of ambient dose equivalent rate range in an interval from $0.125 \mu \mathrm{Sv} / \mathrm{h}(09.10$; 15.10 .) to $0.17 \mu \mathrm{Sv} / \mathrm{h}$ (08.10.) in rural site (Table 1). An increasing of temperature from $5{ }^{\circ} \mathrm{C}$ to $12{ }^{\circ} \mathrm{C}$ affects the increase of dose equivalent value. Ambient dose equivalent rate range from $0.110 \mu \mathrm{Sv} / \mathrm{h}(10.10$.) to $0.143 \mu \mathrm{Sv} / \mathrm{h}(07.10$.) in urban site (Table 2).

It was raining on the first day of measurements, but in the other days it was sunny, without precipitation. After rain the soil pores are filled with water which impedes exhalation. It is evident from Table 1 and Table 2 that humidity influences variation in value of the ambient dose equivalent rate in the first three days of measurement. Radon exhalation from soil depends on precipitation amounts and also diffusion coefficient increase with temperature (Lebedyte et al., 2003).

Table 1. Ambient dose equivalent rate (ADER), the values of wind speed, moisture, temperature during 15 days in rural site

\begin{tabular}{|c|c|c|c|c|}
\hline Date & $\begin{array}{c}\text { ADER } \\
(\mu \mathrm{Sv} / \mathrm{h})\end{array}$ & $\begin{array}{c}\text { Wind } \\
(\mathrm{km} / \mathrm{h})\end{array}$ & $\begin{array}{c}\text { Moisture } \\
(\%)\end{array}$ & $\begin{array}{c}\text { Temperature } \\
\left({ }^{\circ} \mathrm{C}\right)\end{array}$ \\
\hline 07.10. & 0.153 & 26 & 99 & 5 \\
\hline 08.10. & 0.170 & 15 & 97 & 12 \\
\hline 09.10. & 0.125 & 13 & 84 & 14 \\
\hline 10.10. & 0.145 & 8 & 53 & 17 \\
\hline 11.10. & 0.128 & 16 & 58 & 17 \\
\hline 12.10. & 0.133 & 8 & 56 & 18 \\
\hline 13.10. & 0.133 & 11 & 59 & 19 \\
\hline 14.10. & 0.143 & 12 & 60 & 18 \\
\hline 15.10. & 0.125 & 5 & 57 & 16 \\
\hline 16.10. & 0.140 & 2 & 66 & 21 \\
\hline 17.10. & 0.148 & 3 & 42 & 25 \\
\hline 18.10. & 0.150 & 6 & 37 & 27 \\
\hline 19.10. & 0.153 & 3 & 34 & 26 \\
\hline 20.10. & 0.155 & 0 & 42 & 24 \\
\hline 21.10. & 0.133 & 4 & 74 & 23 \\
\hline
\end{tabular}


Table 2. Ambient dose equivalent rate (ADER), the values of wind speed, moisture, temperature during 15 days in urban site

\begin{tabular}{|c|c|c|c|c|}
\hline Date & $\begin{array}{c}\text { ADER } \\
(\mu \mathrm{Sv} / \mathrm{h})\end{array}$ & $\begin{array}{c}\text { Wind } \\
(\mathrm{km} / \mathrm{h})\end{array}$ & $\begin{array}{c}\text { Moisture } \\
(\%)\end{array}$ & $\begin{array}{c}\text { Temperature } \\
\left({ }^{\circ} \mathrm{C}\right)\end{array}$ \\
\hline 07.10. & 0.143 & 27 & 99 & 4 \\
\hline 08.10. & 0.120 & 16 & 97 & 12 \\
\hline 09.10. & 0.123 & 13 & 84 & 14 \\
\hline 10.10. & 0.110 & 8 & 53 & 17 \\
\hline 11.10. & 0.113 & 14 & 58 & 17 \\
\hline 12.10. & 0.125 & 8 & 56 & 18 \\
\hline 13.10. & 0.133 & 11 & 59 & 19 \\
\hline 14.10. & 0.125 & 12 & 60 & 21 \\
\hline 15.10. & 0.123 & 9 & 57 & 22 \\
\hline 16.10. & 0.138 & 3 & 57 & 23 \\
\hline 17.10. & 0.138 & 2 & 49 & 26 \\
\hline 18.10. & 0.138 & 10 & 37 & 27 \\
\hline 19.10. & 0.138 & 3 & 33 & 26 \\
\hline 20.10. & 0.128 & 12 & 42 & 26 \\
\hline 21.10. & 0.123 & 5 & 74 & 24 \\
\hline
\end{tabular}

The high humidity with wind speed of $27 \mathrm{~km} / \mathrm{h}$ during first days affects diurnal changes in the values of dose rates. These values decrease as humidity decreases in the coming days; somehow stable values of ambient dose equivalent rates are established. This was due to a gradual (from day to day) decrease of the wind speed and an increase in air temperature, which influence slightly increasing the dose equivalent rate.

Descriptive statistics of ambient dose equivalent rate for both, rural and urban site is presented in Table 3. Mean ambient dose equivalent rate in rural site $(142 \mathrm{nSv} / \mathrm{h})$ is higher than in urban site $(128 \mathrm{nSv} / \mathrm{h})$. Similar value for median, low values of standard deviation and skewness indicate normal distribution of results.

Table 3. Descriptive statistics of ambient dose equivalent rate measurements in rural and urban sites

\begin{tabular}{|l|r|r|}
\hline Parameters & Rural site & Urban site \\
\hline Minimum & 125 & 110 \\
\hline Maximum & 170 & 143 \\
\hline Mean & 142 & 128 \\
\hline Median & 143 & 125 \\
\hline Standard Deviation & 12.9 & 9.7 \\
\hline Skewness & 0.45 & -0.18 \\
\hline Kurtosis & -0.20 & -0.82 \\
\hline
\end{tabular}

Apparently from Fig. 1, diurnal ambient dose equivalent rate for certain period is higher in the rural than in the urban site. In addition to the difference in altitude which may be reason of such results, the difference can also be due to the environment itself, including the composition of soil and geological features, since rural site is located on the slope of the mountain Jastrebac.

A weak correlation was found between measurements in rural and urban sites; Pearson coefficient, $r$ was 0.3. There is no correlation between ambient dose equivalent rate and any noted parameter (wind speed, moisture, temperature).

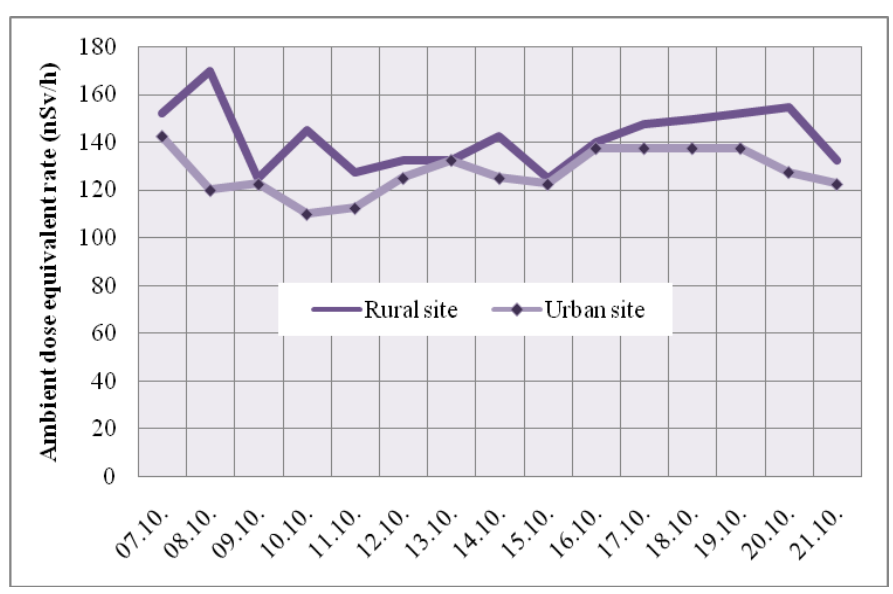

Figure 1. Values of ambient dose equivalent rates in test field during fifteen days of October 2017.

Obtained results are in good agreement with values of ambient dose equivalent rate measured in Republic of Serbia in 2015, which varied from 81 to $142 \mathrm{nSv} / \mathrm{h}$ (Serbian Radiation Protection and Nuclear Safety Agency, 2016). The range of ambient dose equivalent rate from this study $(110-170 \mathrm{nSv} / \mathrm{h})$ is comparable with other results obtained for specific sites of lead, cink and phosfate ores in Raška (70-150 nSv/h) and Bosilegrad (78-123 nSv/h) (Todorović et al., 2012).

In this study background radiation levels were preliminary registered in test field by measuring the ambient dose equivalent rates. The influences of weather conditions and spatial characteristics on obtained results were analyzed.

\section{CONCLUSION}

Preliminary measurements of the ambient dose equivalent rates in test field showed that the mean value of the ambient dose equivalent rate during fifteen days in the urban site was always lower than in rural site. The reasons are the joint influences of weather variations in temperature, humidity, wind speed, precipitation, since these parameters are interrelated and interdependent and the exact influence of each parameter is not possible to determine. Also, the higher altitude of the rural site in comparison with urban, and the geographical location near hilly terrain may have impact on measured values of ambient dose equivalent rates.

The moisture influences variation in value of the ambient dose equivalent rate. Although an increasing of temperature, decreasing the moisture in air, and slowing down the wind speed during the observed period showed tendency of stability 
the ambient dose equivalent rate, no correlation was found between ambient dose equivalent rate and any parameter (wind speed, moisture, temperature).

\section{ACKNOWLEGMENTS}

The paper is a part of the research done within the project no. III41028 supported by the Ministry of Education, Science and Technology Development of the Republic of Serbia and the project no. IJ01-17 supported by the Faculty of Natural Sciences and Mathematics, University of Priština, Kosovska Mitrovica. The author is grateful to Mrs. Danijela Aleksić for field work.

\section{REFERENCES}

Abba, H.T., Hassan, W.M.S.W., Saleh, M.A., Aliyu, A.S., \& Ramli, A.T. 2017. Terrestrial gamma radiation dose (TGRD) levels in northern zone of Jos Plateau, Nigeria: Statistical relationship between dose rates and geological formations. Radiation Physics and Chemistry, 140, pp. 167-172. doi:10.1016/j.radphyschem.2017.01.023

Bossew, P., Cinelli, G., Hernández-Ceballos, M., Cernohlawek, N., Gruber, V., Dehandschutter, B., . . . de Cort, M. 2017. Estimating the terrestrial gamma dose rate by decomposition of the ambient dose equivalent rate. Journal of Environmental Radioactivity, 166, pp. 296308. doi:10.1016/j.jenvrad.2016.02.013

Bouville, A. \& Lowder W.M. 1988. Human population exposure to the cosmic radiation. Radiation Protection Dosimetry, 24, pp. 293-299. doi:10.1093/oxfordjournals.rpd.a080290

Gulan, Lj., \& Spasović, L. 2017. Outdoor and Indoor Ambient Dose Equivalent Rates in Berane Town, Montenegro. In RAD5 Proceeding of Fifth International Conference on radiation and applications in various fields of research.RAD Association. doi:10.21175/radproc.2017.28

Lebedyte, M., Butkus, D., \& Morkūnas, G. 2002. Variations of the ambient dose equivalent rate in the ground level air. Journal of Environmental Radioactivity, 64(1), pp. 4557. doi:10.1016/s0265-931x(02)00057-7
-RADEX. 2017. Radiation Detector RD1503+. Retrieved from: https://www.quartarad.ru/en/catalog/dozimetrradiometr-radon/dozimetr-radexrd1503/.

Sanusi, M.S.M., Ramli, A.T., Gabdo, H.T., Garba, N.N., Heryanshah, A., Wagiran, H., \& Said, M.N. 2014. Isodose mapping of terrestrial gamma radiation dose rate of Selangor state, Kuala Lumpur and Putrajaya, Malaysia. Journal of Environmental Radioactivity, 135, pp. 67-74. doi:10.1016/j.jenvrad.2014.04.004

-Serbian Radiation Protection and Nuclear Safety Agency. 2016. Annual Report of population exposure to ionizing radiation in 2015.Belgrade, Republic of Serbia. in Serbian.

Stojanovska, Z., Boev, B., Zunic, Z.S., Ivanova, K., Ristova, M., Tsenova, M., . . . Bossew, P. 2016. Variation of indoor radon concentration and ambient dose equivalent rate in different outdoor and indoor environments. Radiation and Environmental Biophysics, 55(2), pp. 171-183. doi:10.1007/s00411-016-0640-y

Todorović, D.J., Janković, M.M., Nikolić, J.D., \& Kosutić, D.D. 2012. Radioactivity of mining sites of lead, zinc and phosphate ores in Serbia. Journal of Environmental Science and Health, Part A, 47(6), pp. 812-817. doi:10.1080/10934529.2012.664992

-United Nations Scientific Committee on the Effects of Atomic Radiation (UNSCEAR). 2000. Sources and effects of ionizing radiation: Report to General Assembly with Scientific Annexes.New York.

-United Naations Scientific Committee on the Effects of Atomic Radiation (UNSCEAR). 2010. Sources and effects of ionizing radiation. Annex B: Exposure of the public and workers from various sources of radiation. New York.

Vuckovic, B., Gulan, Lj., Milenkovic, B., Stajic, J.M., \& Milic, G. 2016. Indoor radon and thoron concentrations in some towns of central and South Serbia. Journal of Environmental Management, 183, pp. 938-944. doi:10.1016/j.jenvman.2016.09.053

Wang, Z. 2002. Natural radiation environment in China. International Congress Series, 1225, pp. 39-46. PII: S05315131(01)00548-9 